\title{
Escola Inclusiva: Articulação Curricular
}

Maria José da Silva Bezerral'; Gislene Farias de Oliveira ${ }^{2}$

Resumo: Este artigo tem o objetivo de fazer uma reflexão acerca da relação do currículo, sala de AEE (Atendimento Educacional Especializado) e sala de aula regular dentro da escola inclusiva. Como enfrentar esses desafios contemporâneos da educação e superá-los para atender a todos os alunos de forma igualitária? Com a finalidade de conhecer melhor a inclusão e como fazer acontecer de fato na sala regular, dentro de uma perspectiva de ensino adequado para minimizar os problemas existentes e promover uma educação inclusiva.

Palavras chave: Escola inclusiva, currículo, sala de AEE, sala regular

\section{Inclusive School: Curriculum Coordination}

\begin{abstract}
This article aims to take a reflection on the curriculum relation ESS room (Educational Service Specialized) and regular classroom within the inclusive school. How to face these contemporary challenges of education and overcome them to meet all students equally? In order to learn more about inclusion and how to actually happen in the regular room, within an appropriate teaching perspective to minimize existing problems and promote inclusive education.
\end{abstract}

Keywords: Inclusive school, curriculum, ESS room, regular room

\section{Introdução}

O propósito da escola inclusiva é que todos sejam iguais em suas diferenças. A igualdade, entre alunos, de oportunidade de aprender e desenvolver suas habilidades na sala de aula regular com o apoio de adaptações curriculares e da sala de AEE é direito de todos. Sendo assim, esse estudo bibliográfico procura refletir sobre essa relação dentro da escola dita inclusiva. Cada instrumento tem as suas atribuições que deverão ser aprimoradas e reorganizadas pedagogicamente para atender a todos os alunos de forma igualitária dentro das diferenças e necessidades de cada um.

\footnotetext{
${ }^{1}$ Graduada em Licenciatura do Ensino Fundamental. Especialização em Língua Portuguesa e Arte Educação pela URCA. Email: mazebezerra@bol.com.br

${ }^{2}$ Psicóloga, doutorado em psicologia social pela UFPB e Pós Doutorado em Ciências da Saúde na Faculdade de Medicina do ABC. Santo André - São Paulo. Professora Associada da Universidade Regional do Cariri - URCA e professora adjunta da Universidade Federal do Ceará - UFC. Email: gislenefarias@ gmail.com
} 
Id on Line Revista Multidisciplinar e de Psicologia

Id on Line Multidisciplinary and Psycology Journal

Começando por uma reflexão sobre a escola inclusiva, que deve acompanhar as necessidades de todos os alunos para evitar a exclusão, chega-se ao currículo e suas adaptações para o atendimento adequado dos alunos, principalmente com necessidades educacionais especiais que com o apoio da sala de AEE e o profissional que a conduz, irá acontecer uma melhor integração com o professor da sala de ensino regular e assim proporcionar uma reflexão conjunta na condução do processo de inclusão.

Com essa perspectiva de inclusão e cooperação, unindo currículo, sala de AEE, comunidade escolar como um todo e a sala regular, é que se busca uma educação que proporcione a todos desenvolver suas habilidades e suas potencialidades educacionais e sociais.

\section{A Escola Inclusiva}

O princípio de igualdade tão difundido pela sociedade e a proibição de discriminação é direito de todos. As crianças com necessidades educacionais especiais atendidas pela escola regular devem ser tratadas normalmente como seus pares, e como todos os outros, serem acompanhadas nas suas necessidades individuais, contribuindo para a melhoria da qualidade do ensino em geral. Incluir não é só colocar na sala de aula, é fundamental o desenvolvimento, no seu tempo, do seu modo, mas sempre visando o acesso, o avanço e a permanência na escola com um ensino de qualidade e o preparo para o exercício da cidadania.

O Atendimento educacional especializado, previsto como acréscimo e não como alternativa, nas escolas, nas salas de AEE, funciona como a concretização do direito à educação. É um complemento ao trabalho realizado na sala regular, um apoio ao aluno com necessidades educacionais especiais, como também ao professor que nem sempre está preparado para tal evento.

Como afirma Fávero $(2007,18)$ "o que se persegue, especialmente em fase de Ensino Fundamental, é a formação humana e a preparação emocional do aluno para prosseguir nos estudos". Sendo assim, o aluno com deficiência deverá ser atendido na sala regular sem descuido do conteúdo curricular, mas visando sempre o seu desenvolvimento humano. Ensinar toda a turma deve ser o foco principal para que não haja exclusão, levando-se em conta o nível de desenvolvimento das habilidades de cada um. 
Persiste a ideia de que as escolas consideradas de qualidade são as que centram a aprendizagem nos conteúdos programáticos das disciplinas curriculares, exclusivamente; as que enfatizam o aspecto cognitivo do desenvolvimento e que avaliam os alunos, quantificando respostas-padrão. Suas práticas preconizam a exposição oral, a repetição, a memorização, os treinamentos, o livresco, a negação do valor do erro. São aquelas escolas que estão sempre preparando o aluno para o futuro: seja este o próximo ano a ser cursado, o nível de escolaridade posterior ou o vestibular! (MANTOAN, 2007, 52).

O desafio de uma escola inclusiva se inicia quando o lado humano e a aproximação dos alunos entre si são explorados com o propósito de aglutinar esforços para o conhecimento mútuo, das famílias e de toda a comunidade escolar.

\footnotetext{
Nas "práticas não - disciplinares" de ensino predominam a experimentação, a criação, a descoberta, a co - autoria do conhecimento. Essas práticas estão voltadas para o ensino de temas, de assuntos de interesse da turma. Nelas os conteúdos disciplinares não são fins em si mesmos. As escolas que as adotam são espaços educativos de construção de personalidades humanas autônomas, críticas, nos quais as crianças aprendem a ser pessoas. Nelas os alunos são ensinados a valorizar as diferenças, pela convivência com seus pares, pelo exemplo dos professores, pelo ensino ministrado nas salas de aula, pelo clima sócio - afetivo das relações estabelecidas em toda comunidade escolar. (MANTOAN, 2007, 53)
}

Nesse modelo de prática não há exclusão e sim colaboração de experiências e habilidades em todos os processos pedagógicos. Além das atividades diversificadas e significativas que atendam a todos os níveis de aprendizagem. Outro momento importante é a avaliação que também deve mudar e acompanhar os desafios do ensino numa perspectiva inclusiva. Avaliar torna-se algo onde o progresso do aluno, a organização dos estudos, a participação na vida social é entendida como pontos diferentes da avaliação classificatória.

É importante que o professor saiba como utilizar o conhecimento prévio do aluno e acreditar que todos possam aprender e os seus talentos devem ser explorados e suas limitações e dificuldades reconhecidas, identificadas e superadas através da interação e construção de conceitos, valores e atitudes dentro de uma lógica pedagógica.

Deve-se reconhecer que na escola as turmas são heterogêneas e, portanto, o ensino precisa ser baseado nas diferenças e acontecer de forma democrática. E para isso, os profissionais devem ser preparados, acompanhados nas suas necessidades com planejamentos e formações adequadas. 
Uma das maiores preocupações no processo de inclusão é justamente a falta de preparação dos profissionais docentes. Preparação esta relacionada a termos de mudanças de representações, no conceito do que é educar e para quem educar; termos de valores em relação ao outro e dos recursos pessoais, que permitam o trabalho pedagógico criativo, que é fator indispensável à inclusão. (MENDONÇA, 2011, 20)

Com o conhecimento concreto das necessidades dos alunos com deficiência, desde a formação inicial ou permanente, o professor poderá realizar um trabalho com mais eficácia e a escola será realmente inclusiva e cumprir o seu papel na sociedade contemporânea.

\title{
Adaptação do currículo na escola inclusiva
}

A inclusão social é constituída no espaço da inclusão escolar, nesse contexto a escola é promotora da inclusão e contribui para o extermínio da segregação das pessoas com deficiências. É delegada à escola a responsabilidade do ensino sistematizado e consequentemente as habilidades e competências fundamentais à vida social. Sendo assim a mudança deve começar pelo currículo. È importante verificar se a organização curricular legal e necessária está se efetivando no dia a dia da escola para que realmente seja concebida como inclusiva. A princípio a escola inclusiva deve acolher o aluno com necessidades educacionais especiais com a expectativa de averiguar suas potencialidades e possíveis avanços na aprendizagem.

\begin{abstract}
Nesse sentido, espera-se que o professor saiba acolher a diversidade e desenvolver aprendizagem em seus alunos, levando em consideração a diversidade nos estilos de aprendizagem e ritmos que se encontram presentes em sua sala de aula. Por isso é que a escola precisa adaptar-se às necessidades dos alunos, e para tal, destaca-se a necessidade de um currículo flexível, abrangendo uma proposta de conteúdos a partir da realidade de cada escola com base na sua autonomia, onde os elementos curriculares adquirirão novas formas, ou seja, os conteúdos não serão memorizados, mas aprendidos compreensivamente; a relação de professor e alunos será de parceria; as metodologias serão variadas e ativas; a avaliação não será a cobrança da falta ou o reforço do comportamento obediente, mas a análise do processo para reorganizar as ações no cotidiano escolar. (SILVA e MOREIRA, 2008)
\end{abstract}

A demanda de alunos com necessidades educacionais especiais, só aumenta e é necessário que a prática pedagógica caminhe junto com a teoria. O currículo deve ser aberto à diversidade, ou seja, os alunos podem aprender de diferentes maneiras. Ao planejar, o professor deve estabelecer expectativas e criar oportunidades concretas para atingir os objetivos de 
Id on Line Revista Multidisciplinar e de Psicologia

Id on Line Multidisciplinary and Psycology Journal

aprendizagem de todos os alunos, incluindo todos em suas diferenças. Mediante o currículo apropriado, metodologias diversificadas, parcerias com a comunidade escolar, entre outras medidas, a escola poderá implementar uma educação inclusiva, assegurando as adaptações às necessidades dos alunos.

Sem conhecer os seus alunos e os que estão à sua margem, não é possível à escola elaborar um currículo que reflita o meio social e cultural em que se insere. A integração entre áreas do conhecimento e a concepção transversal das novas propostas de organização curricular consideram as disciplinas acadêmicas como meios e não fins em si mesmas e partem do respeito à realidade do aluno, de suas experiências de vida cotidiana, para chegar a sistematização do saber. (MANTOAN, 2001, 114)

Nesse contexto, conhecer o aluno individualmente e o meio em que vive, torna-se prioridade na hora de colocar o currículo em prática. Também a organização da sala, o número de alunos e a preparação dos profissionais devem ocorrer concomitantemente com as adaptações curriculares para que a heterogeneidade contribua na construção dos saberes e consequentemente a promoção do sucesso de todos.

Precisamos, assim, de um professor que, para além das áreas conteudísticas habituais de formação possa ainda, conhecer e desenvolver um conjunto de práticas que permita aos alunos alcançar o sucesso, isto é, atingirem o limite superior das suas capacidades. (RODRIGUES, 2008, p.7)

Portanto, o professor da escola inclusiva deve ser preparado com o intuito de trabalhar com a heterogeneidade, com as adaptações curriculares necessárias, considerando as mudanças no planejamento, nas intervenções pedagógicas e na avaliação.

\section{A sala de Atendimento Educacional Especializado - AEE}

A escola inclusiva que oferta serviços pedagógicos e de acessibilidade através da sala de AEE, deve colaborar nas mudanças das práticas pedagógicas nas salas de aula regulares, como por exemplo, a pedagogia interativa, interdisciplinar, significativa, dialógica, estimulando as capacidades dos alunos. A sala de AEE é um apoio fundamental na escola inclusiva, funcionando em articulação com a classe comum, como também, com as famílias 
dos alunos com necessidades educacionais especiais que devem ser parceiras nesse atendimento.

O professor de AEE oferece acompanhamento em sala de aula para ensinar o uso de recursos destinados aos alunos com deficiência aos professores e demais alunos. O professor do AEE deve identificar e desenvolver estratégias educativas visando à superação das dificuldades de aprendizagem dos alunos. Ele inclui em suas ações: avaliação do aluno, a gestão do seu processo de aprendizagem e acompanhamento desse auno na sala de recursos multifuncionais (espaço destinado para realização do AEE) e na interlocução com o professor do ensino comum. (FIGUEIREDO, 2010, 34)

A colaboração de todos na escola inclusiva é imprescindível para somar esforços e valorizar a participação de cada membro no acompanhamento que permita ações proativas no desenvolvimento da aprendizagem compartilhada por todos os alunos. A articulação da sala de AEE e a sala regular passa pelos desafios da escolarização de todas as crianças implementada pelas redes públicas de ensino.

Esta política pública assegurada por lei só será realmente efetivada com a criação de condições necessárias e transformações para o ensino e a aprendizagem de fato, focando como ponto principal as necessidades dos educandos. Nesse sentido, o professor da sala de AEE será um grande apoio e incentivador do professor da sala regular.

O professor de AEE é um profissional que atua sobre as peculiaridades de certos alunos, provendo recursos, meios, equipamentos, linguagens e conhecimentos que os apoiam no acesso e participação no ensino comum. Seu trabalho vai além do ensino de técnicas, códigos, manuseios, treino de uso dos recursos que dão suporte à escolarização dos alunos nas turmas comuns e não visam à aprendizagem de conteúdos das áreas curriculares. Trata-se de um professor especializado nesse tipo de atendimento, mas que não se confunde com o especialista no sentido usual do termo, porque ele é, antes de tudo, um professor, cujo entendimento da educação especial na perspectiva inclusiva, permite que ele integre sua especialidade ao ensino comum, sem desfigurá-la. Esse professor pesquisa estuda cada um dos alunos que lhe é encaminhado e decide, organiza, cria, desenvolve recursos para além do que já existe de suportes de todo tipo, que possam suprir as necessidades de cada um. (MANTOAN, 2010, 14)

A parceria do professor da sala de AEE e o professor da sala comum é fundamental para o avanço do aluno com necessidades educacionais especiais, mediante a articulação de ações entre ambos, envolvendo as dificuldades de todos os alunos. O equilíbrio mútuo beneficia a formação do aluno e consequentemente a inclusão. 
Id on Line Revista Multidisciplinar e de Psicologia

Id on Line Multidisciplinary and Psycology Journal

\section{A sala de aula regular e a inclusão}

A sala de aula inclusiva é um grande desafio na atualidade, visto que além da heterogeneidade, o professor ainda tem que lidar com salas lotadas e se desdobrar em atenção e atendimento a todos. A colaboração entre os professores é imprescindível na condução das ações pedagógicas. O planejamento cooperativo das tarefas educativas deve contemplar à todos em suas necessidades de aprendizagem, utilizando de forma colaborativa o conhecimento e os recursos existentes. A responsabilidade compartilhada dos professores contribui para alcançar os resultados almejados na busca dos objetivos, derrubando as barreiras do individualismo. A participação da família em contato constante com os professores, colaborando nas tarefas educativas ativamente, valorizando e resgatando a auto - estima do alunado, criando assim, laços interativos garantindo que todos se sintam respeitados nas suas diferenças.

A sala de aula inclusiva deve ser concebida como um espaço social e didático que reflita a cultura, valores e metas da escola. A sala de aula é além disso, uma comunidade de aprendizagem autônoma que requer uma nova organização para chegar a ser inclusiva. (DIÉZ, 2010, 23)

Portanto, uma sala de aula inclusiva pressupõe acolhimento e valorização de todos os alunos, trazendo benefícios para a aprendizagem, o desenvolvimento social e a autonomia dos alunos com e sem deficiência. $\mathrm{O}$ aluno com deficiência precisa ser sempre encorajado, ele pode aprender de forma diferente ou levar mais tempo, mas alguma coisa será aprendida. A dificuldade de aprendizagem é um desafio a ser enfrentado com bom senso. O professor não pode tudo, mas ajudará o educando de alguma forma, por exemplo o material do aluno com deficiência pode ser adaptado, mas não diferente dos seus colegas de classe. Ele precisa compartilhar a aprendizagem com seus pares.

A construção de uma cultura inclusiva na sala de aula trará ao alunado oportunidades de aprender em conjunto não só os conteúdos, mas a própria convivência no dia a dia, excluir a discriminação e o preconceito. Incluir a família na comunidade escolar com mais efetividade. Comunicar-se com os pais e colegas professores traz benefícios para as classes, mesmo que seja a longo prazo. Quando a escola formar a consciência da realidade humana entre todos, alunos, professores, famílias, enfim toda a comunidade, então a escola poderá ser considerada realmente inclusiva. 


\section{Considerações finais}

A escola inclusiva só tem a acrescentar à sociedade quando evita a segregação de alunos com necessidades educacionais especiais, pois a convivência agrega e desenvolve as habilidades e competências tanto dos alunos como dos professores, que se qualificam no assunto e têm novas ideias de como trabalhar com toda a clientela.

A heterogeneidade ensina como tratar todos com igualdade e ao mesmo tempo influencia na reorganização curricular e em cada sala de aula com suas peculiaridades, privilegiando as melhorias das práticas educativas.

As adaptações curriculares e o apoio da sala de AEE são importantes para o bom andamento da escola inclusiva, como também a cooperação dos professores entre si e de todos que formam a comunidade escolar.

Esse estudo foi muito importante, acrescentando informações sobre a necessidade de conhecer e se qualificar no assunto, visando o desenvolvimento com projetos construídos dentro de cada realidade e sobretudo o empenho de todos da comunidade escolar em prol da educação inclusiva de qualidade.

\section{Referências}

DIÉZ, Anabel Mariña. Traçando os mesmos caminhos para o desenvolvimento de uma educação inclusiva. Inclusão: Revista de Educação Especial. V 5. No 1 jan/julho.

Secretaria de Educação Especial MEC Brasília: 2010

FÁVERO, Eugênia Augusta Gonzaga, PANTOJA, Luisa de Marillac P., MANTOAN, Maria Teresa Eglér. Atendimento Educacional Especializado: aspectos legais e orientações pedagógicas. MEC/SEESP. São Paulo: 2007

FIGUEIREDO, Rita Vieira de. Incluir não é inserir, mas interagir e contribuir. Inclusão: Revista da Educação Especial V 5 N$^{\circ} 2$ julho/dezembro. Secretaria de Educação Especial MEC Brasília: 2010 
MANTOAN, Maria Teresa Eglér. O atendimento educacional especializado na educação inclusiva. Inclusão: Revista da Educação Especial V5 Nº1 jan/julho. Secretaria de Educação Especial MEC Brasília: 2010

(org.) Por uma escola (de qualidade) para todos. In:

Pensando e fazendo educação de qualidade. São Paulo: Moderna. 2001

MENDONÇA, Regina Celia Avilha. A aprendizagem do aluno com deficiência intelectual e a prática pedagógica em questão. Universidade de Brasília. Monografia apresentada ao curso de Educação e Inclusão. Brasília, 2011. Disponível em bdm.unb.br/pdf Acesso em $20 / 08 / 2016$

RODRIGUES, Davi. Desenvolver a educação inclusiva: dimensões do desenvolvimento profissional. Inclusão: Revista da Educação Especial V4 ํ2 julho/outubro. Secretaria de Educação Especial MEC. Brasília, 2008

SILVA, Vanessa Caroline, MOREIRA, Laura Ceretta. Currículo na escola inclusiva: o estigma da diferença. 2008. Disponível em www Pucpr.br Acesso em 26/08/2016

Como citar este artigo (Formato ABNT):

BEZERRA, M.J.S.; OLIVEIRA, G.F. Escola Inclusiva: articulação curricular. Id on Line Revista Multidisciplinar e de Psicologia, Out-Nov. de 2016, vol.10, n.31, Supl 3, p. 237-245. ISSN: 1981-1179.

Recebido: 05/09/2016

Aceito: 15/09/2016 